\title{
Effect of Distal Masseter to Facial Nerve Transfer in Paralytic Patients with Preserved Facial Nerve Continuity on Improving Scaled Measurement of Improvement in Lip Excursion (SMILE): A Vectoral Analysis
}

\author{
Original Investigation \\ Berke Özücer (1), Osman Halit Çam (i) \\ Department of Otorhinolaryngology, Başkent University School of Medicine, İstanbul, Turkey
}

Abstract

ORCID iDs of the authors:

B.0.0000-0001-7798-6793;

O.H.C.. 0000-0002-2785-4474.

Cite this article as: Özücer B, Çam OH. Effect of Distal Masseter to Facial Nerve Transfer in Paralytic Patients with Preserved Facial Nerve Continuity on Improving Scaled Measurement of Improvement in Lip Excursion (SMILE): A

Vectoral Analysis. Turk Arch Otorhinolaryngol 2020; 58(4): 249-53.

\section{Corresponding Author:}

Berke Özücer; berkeozucer@gmail.com

Received Date: 29.07.2020

Accepted Date: 2.11 .2020

Content of this journal is licensed under a Creative Commons Attribution 4.0 International License. Available online at www.turkarchotolaryngol.net
Objective: Distal masseter-to-facial neurorrhaphy is an option to improve smile excursion in facial paralysis patients in the early period without truncating the facial nerve truncus and by ensuring the continuity of the facial nerve. This study aimed to study the effect of distal masseter-to-facial neurorrhaphy on smile excursion.

Methods: Charts of eight patients were retrospectively examined. Screenshots showing the best possible smiles were taken from preoperative videos. Screenshots were taken from postoperative videos showing the best combination of a natural smile on the healthy side and a smile with clenched teeth on the paralytic side. Emotrics and Photoshop software were used for computing vertical, horizontal, and overall excursion from facial landmarks. Scaled measurements of improvement in lip excursion and lip angle was evaluated. Symmetry was evaluated by accepting the healthy side as 100 percent, and the paralytic side was calculated as a percentage of the healthy side.

Results: Five patients had total facial paralysis and three had facial paresis. Mean postoperative follow-up period was $15.0 \pm 10.2$ months. The average

\section{Introduction}

Facial paralysis is a disabling disease associated with depression and severe decrease in life quality (1). Numerous facial reanimation techniques are described to address facial paralysis. Recently, paralytic patients with anatomically and physically preserved nerve continuity present as a dilemma; two practical approaches are possible: (a) conservatively waiting for spontaneous recovery, (b) or early intervention by connecting additional nerve input from other cranial nerves. Denervation time is a factor that interval between facial denervation and nerve repair was $14.0 \pm 4.1$ months (range, 11-23). All neurorrhaphies were coapted end-to-end to either the zygomatic or the buccal branch without an interposition graft. Mean postoperative initial movement occurred at $95.5 \pm 20.5$ days (range, $72-138$ ). Paralytic side to healthy side horizontal excursion changed from preoperative $72.5 \pm 17.4 \%$ to postoperative $93.4 \pm 6.9 \%$. Vertical excursion changed from preoperative $38.4 \pm 24.6 \%$ to postoperative $89.3 \pm 11.8 \%$. Overall excursion changed from preoperative $68.4 \pm 19.6 \%$ to postoperative $92.9 \pm 10.4 \%$. Paralytic side to healthy side mean lip angle changed from $64.7 \%$ preoperative to $95.2 \%$ postoperatively. All changes were statistically significant $(\mathrm{p}<0.05)$.

Conclusion: Facial paralysis patients with an asymmetric smile benefit from distal masseter-to-facial nerve transfer and it improves smile excursion dramatically. This effect was especially prominent in the vertical component of the smiling vector.

Keywords: Facial paralysis, facial palsy, facial paresis, masseter nerve, smile excursion, facial reanimation makes the timing of the intervention as crucial as the intervention itself. While recent studies have shown that early intervention resulted in more satisfactory results, current literature tends to stress the importance of early intervention (2). Nerve transfer to the facial nerve trunk offers a trade-off of giving up natural facial nerve healing. Neurorrhaphy to distal branches without truncating avoids this trade-off and makes early nerve transfer a viable option.

The masseter nerve, a motor branch of the trigeminal nerve, is a donor nerve described relatively more 
Table 1. Patient data

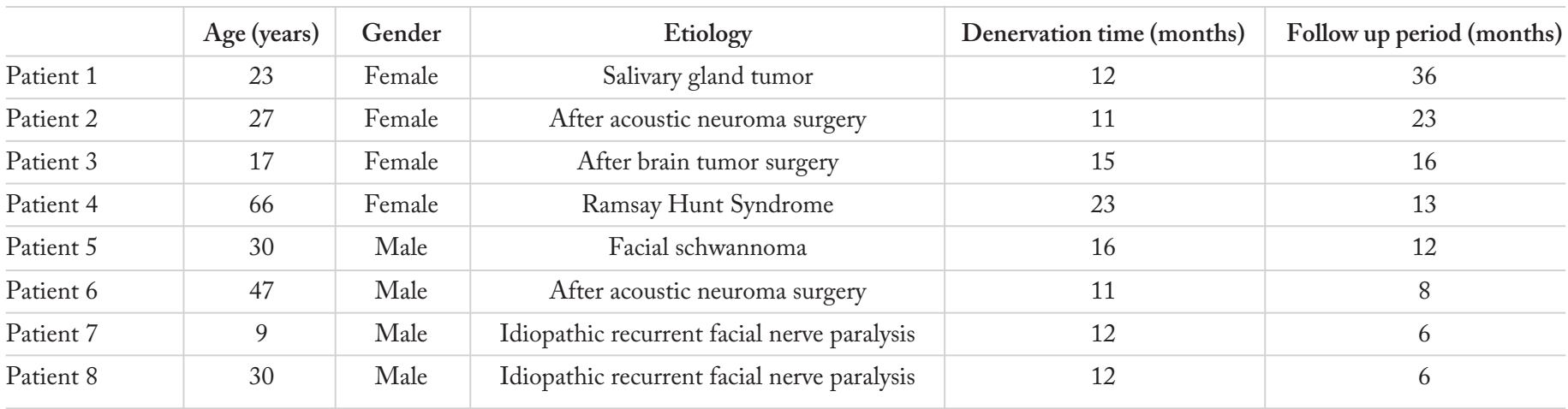

recently by Spira (3) in 1978. It was first described as a donor nerve for free gracilis muscle transfer, but its utilization solely in nerve grafting was reported numerously in the literature $(4,5)$. Its proximity to the surgical field eliminates the need for an interposition graft, and thereby prevents extra morbidity, allowing for theoretically faster and better healing due to single-anastomosis.

This study aimed to evaluate the effects of distal masseter-to-facial nerve transfer in facial palsy patients with preserved facial nerve continuity on improving smile excursion.

\section{Methods}

This study was approved by Başkent University Institutional Review Board (Approval Date: June 16, 2020; Approval Number: KA20/241) and supported by Başkent University Research Fund. Informed consent was obtained from all patients. Records of patients who were operated on from January 2018 to January 2020 were examined consecutively. All patients were operated on by the first author. Truncation of the facial nerve truncus was a criterion for exclusion from the study. Patients were consecutively included, and patient records and surgical notes were retrospectively reviewed. Denervation time and follow-up period were noted for each patient.

\section{Operative Technique}

The operative technique was based on the cadaveric studies by Collar et al. (6) and Borschel et al. (7). In all cases, the masseteric nerve was identified through a limited, minimally invasive dissection following a limited preauricular incision rather than a parotidectomy-like approach. Landmarks of the subzygomatic triangle were marked 3 to $1 \mathrm{~cm}$ measurement as explained by Borschel et al. (7).

\section{Main Points}

- Distal masseter-to-facial nerve transfer is a viable option for early reinnervation without truncating the main facial nerve truncus.

- Mean postoperative initial movement occurred at the third postoperative month.

- Facial paralysis patients with asymmetric smile benefit from distal masseter-to-facial nerve transfer, which improves smile excursion; this improvement is especially dramatic in the vertical vector.
A preauricular incision was carried out with a 15-blade, and subcutaneous dissection was carried out bluntly. Buccal and zygomatic branches that approximate the origin of zygomatic muscle on the zygomatic bone were identified with blunt dissection of a delicate hemostat parallel to the distal branches of the facial nerve. After the recipient branch was identified, the masseter nerve was explored. Basic nerve stimulator (Stimuplex ${ }^{\circledR}$ HNS12 Nerve Stimulator, Braun Medical Inc.; Melsungen, Germany) was used to identify the nerve branches. The masseter nerve in the masseter muscle was dissected; abundant masseter nerve dissection was ensured for a tension-free coaptation without the need for an interposition graft. Approximately 4 to 5 nylon sutures (10-0) were used for end-toend coaptation. All cases were finalized with fibrin sealant (Baxter International Inc.; Illinois, USA). Minivac drains were removed and all patients were discharged on the first postoperative day.

\section{Evaluation}

Evaluations were based on the screenshots taken from the standardized preoperative and postoperative videos of patients. Screenshots of the best possible smiles were taken from the preoperative videos. Screenshots of the best possible combined smiles with a natural smile on the healthy side and a smile with clenched teeth on the paralytic side were taken from the postoperative videos. The Emotrics sofware (Emotrics Software, Mass Eye and Ear; Boston, MA, USA) was used to automatically mark the facial landmarks such as the iris and the facial midline with the software's artificial intelligence algorithm (8) (Figure 1). Best possible smile photos were marked, and scaled measurements of improvement in lip angle and lip excursion (SMILEs) were calculated by vectorial analysis as previously described (9).

\section{Statistical Analysis}

On the healthy side, vertical excursion was marked (y), horizontal excursion was marked (x), and overall excursion was marked (z). On the paralytic side, vertical excursion was marked (y'), horizontal excursion was marked $\left(x^{\prime}\right)$, and overall excursion was marked ( $\left.z^{\prime}\right)$. Vectors on the healthy side were accepted as $100 \%$, and the paralytic side was scale measured relatively as $\left(x / x^{\prime}\right)$ $\mathrm{x} 100$. Preoperative and postoperative values, and change rates were compared with the Wilcoxon Signed Ranks test. IBM Statistical Package for the Social Sciences version 24 (IBM SPSS Corp.; Armonk, NY, USA) was used for statistical analysis. $\mathrm{P}$ values lower than 0.05 were accepted as statistically significant. 


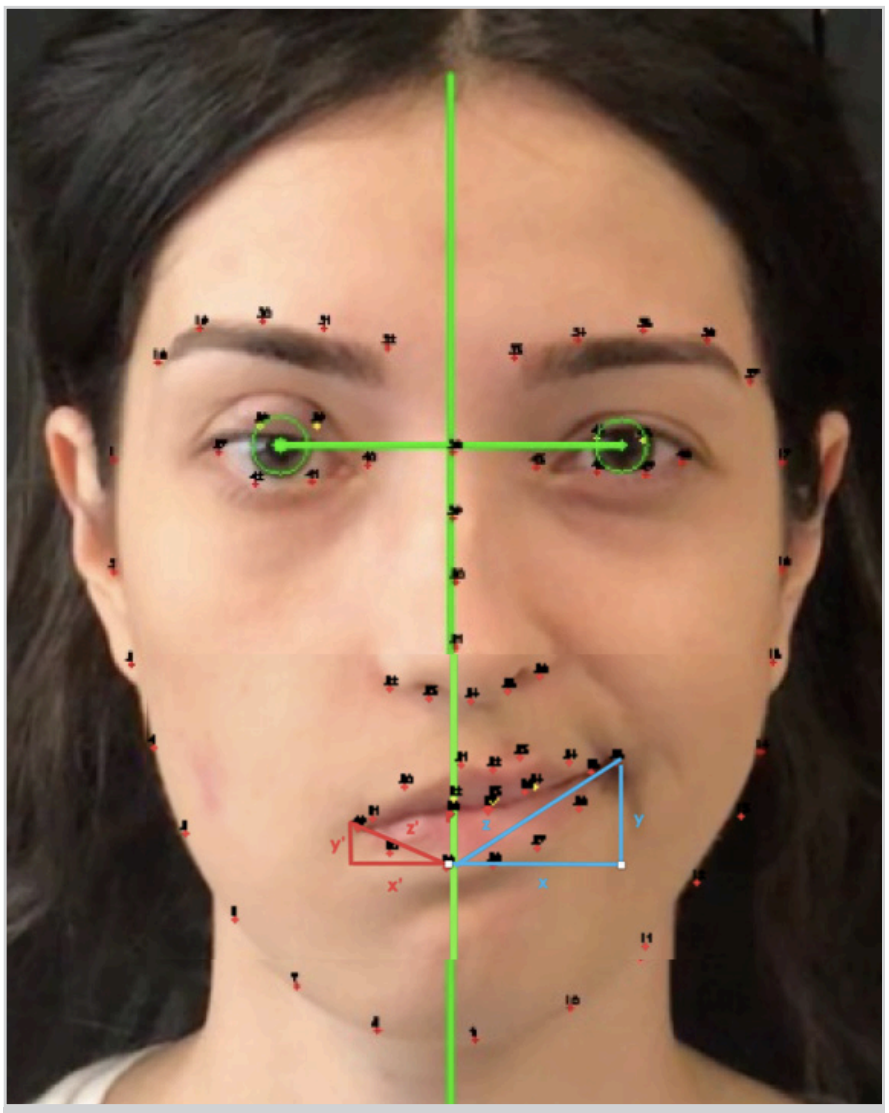

Figure 1. Marking of facial landmarks in Emotrics software and vectoral analysis in pixels via Photoshop

Table 2. SMILE vectoral analysis before and after distal masseterofacial anastomosis

\begin{tabular}{l|c|c|c|c}
\hline & $\begin{array}{c}\text { Preoperative } \\
\mathbf{( \% )}\end{array}$ & $\begin{array}{c}\text { Postoperative } \\
\mathbf{( \% )}\end{array}$ & $\mathbf{p}$ & $\mathbf{z}$ \\
\hline Horizontal lip excursion & 72.5 & 93.4 & 0.036 & -2.100 \\
\hline Vertical lip excursion & 38.4 & 89.3 & 0.012 & -2.521 \\
\hline Overall lip excursion & 68.4 & 92.9 & 0.036 & -2.100 \\
\hline Lip angle & 64.7 & 95.2 & 0.012 & -2.521 \\
\hline
\end{tabular}

\section{Results}

Five patients had total facial paralysis, and three had facial paresis; etiologies are detailed in Table 1. Four patients were male and four were female (Table 1). Mean time between facial denervation and nerve repair was $14.0 \pm 4.1$ months (range, 11-23). Mean postoperative follow-up period was $15.0 \pm 10.2$ months. All neurorrhaphies were coapted end-to-end to either the zygomatic or the buccal branch without an interposition graft. Two of the eight patients received additional static suspension with tensor fascia lata graft for a better resting facial symmetry. Three of the eight patients had undergone upper eyelid gold weight placement at another center, and two had adjunctive upper eyelid golden weight placement. Two patients (25\%) complained about temporary painful and limited oral opening in the early postoperative period, and these were resolved without intervention. Slight atrophy of the masseter was present in some patients, but none opted for filler or fat augmentation.

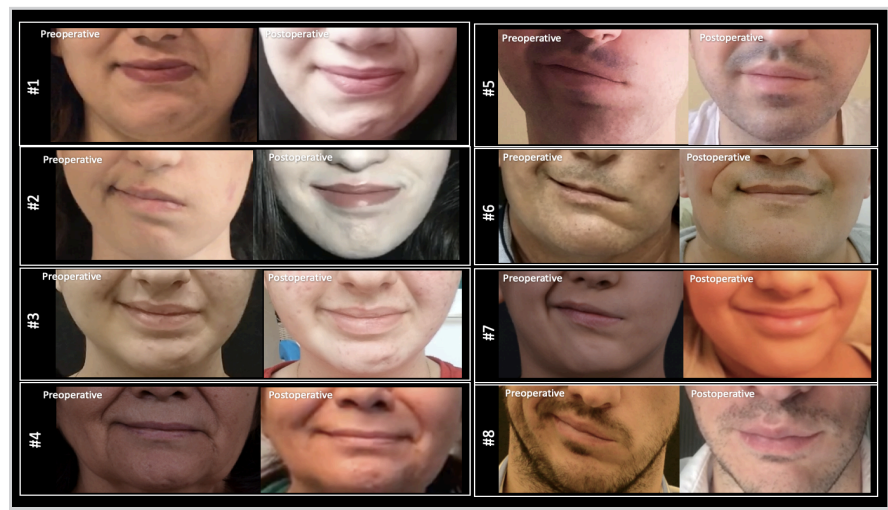

Figure 2. Preoperative and postoperative images of best possible smile

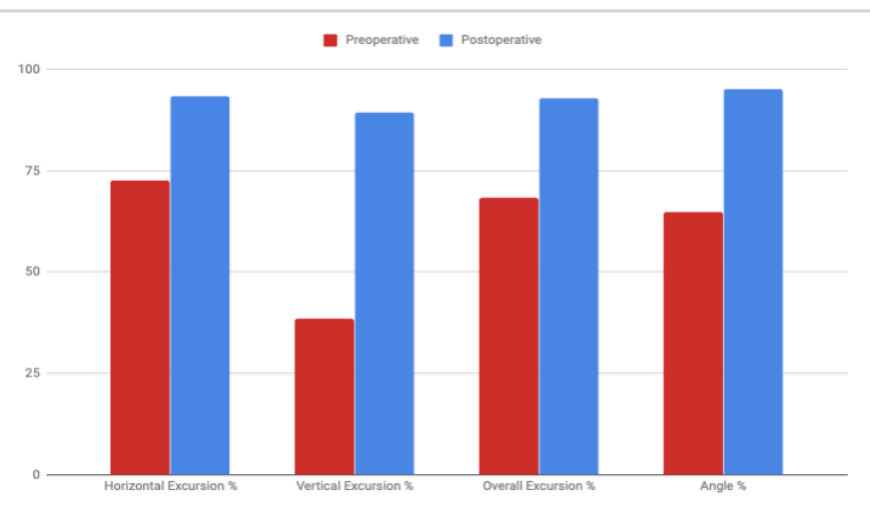

Figure 3. Evaluation of smile excursion vectors and lip angles

Table 3. Pros and cons of using the masseter nerve

\begin{tabular}{l|l} 
Pros & Cons \\
\hline $\begin{array}{l}\text { Proximity to surgical field } \\
\text { asymmetry }\end{array}$ & Masseter muscle atrophy associated \\
\hline $\begin{array}{l}\text { Eliminating the need for an } \\
\text { interposition graft }\end{array}$ & Tonus \\
\hline \begin{tabular}{l} 
Fast healing \\
\hline $\begin{array}{l}\text { Strong excursion } \\
\text { Minimal morbidity }\end{array}$
\end{tabular} & Need for adaptation and physical therapy \\
\hline
\end{tabular}

The mean time to postoperative initial movement was $95.5 \pm 20.5$ days (range, 72-138) (Figure 2). Paralytic side to healthy side horizontal excursion percentage changed from preoperative $72.5 \pm 17.4 \%$ to postoperative $93.4 \pm 6.9 \%$. Vertical excursion percentage changed from preoperative $38.4 \pm 24$. $6 \%$ to postoperative $89.3 \pm 11.8 \%$. Overall excursion percentage changed from preoperative $68.4 \pm 19.6 \%$ to postoperative $92.9 \pm 10.4 \%$ (Figure 3 ). Paralytic side to healthy side mean lip angle changed from $64.7 \%$ preoperative to $95.2 \%$ postoperatively. All changes were statistically significant $(\mathrm{p}<0.05)$; results are further detailed in Table 2.

\section{Discussion}

End-to-end hypoglossal (XII) nerve transfers have historically been the workhorse technique in for facial animation. Jump and other modified hypoglossal nerve transfer procedures were 
introduced to eliminate (a) the need for an interposition graft, (b) a possible hemiglossal atrophy, and (c) the synkinetic mass movement of the face (10).

These three complications and extra donor morbidity can be avoided with masseterofacial anastomosis. Comparison of masseterofacial and hypoglossofacial nerve anastomosis revealed superiority for masseterofacial nerve anastomosis in dynamic movements, whereas, at rest, the hypoglossofacial anastomosis was found slightly better (11). Our study results show that masseterofacial anastomosis of distal facial branches provided a powerful and symmetric smile (Table 2). Nevertheless, it should be noted that adjunct procedures may be required in complete flaccid paralytic patients with a chubby face to achieve symmetric resting tonus. A combination of tensor fascia lata static sling is a viable option.

Our study included the patients with intact facial nerve and branches and those with truncated facial nerve were excluded. This is to say that our results represent a very homogeneous population, and this makes our results reliable. We compared preand postoperative maximum smile images of each patient. To better understand the differences between patients with intact facial nerve and truncated facial nerve, further investigations with a larger sample size are needed.

Masseteric nerve input ensures fast healing due to proximity, which is essential for patients with long denervation time. Nerve transfer to distal facial branches also ensures the continuation of spontaneous healing of the anatomically preserved nerve continuity. Unlike crossfacial nerve grafting, which ensures synchronous facial movements, using the new masseterofacial anastomosis for harmonious mimicry requires learning, practice, and cortical adaptation (Table 3). Rehabilitation and functional recovery after masseterofacial nerve anastomosis is a process that can be expedited with physical therapy (12).

Nevertheless, there are reports in the literature that show that masseter muscle co-activation occurs naturally when smiling. This was shown with electromyography measurements (13). Compared to those performed with non-facial nerve donors, masseterofacial nerve anastomosis seems to be an advantageous option in terms of spontaneity and synchronicity.

There are many surgical treatment strategies for paretic patients about which they were informed during their preoperative visits. The decision-making process was carried out together with the patient. From the patient's aspect, masseterofacial anastomosis alone has the advantages of being a single-stage surgery and not involving the healthy side of the face.

Hontanilla and Marre (14) reported about their experience with masseterofacial anastomosis in nine incomplete paralysis patients that were comparable to our patient series. Frey et al. (15) reported the "facial upgrading" in paretic patients with a procedure which they called distal end-to-side cross-facial nerve grafting $(\mathrm{CFNG})$. In this procedure, distal facial nerve branch of the donor side is transected and coapted end-to-end to the sural nerve graft. Distally, the sural nerve graft is coapted end-to-side following an epineural window. With this procedure, native facial nerve axonal input is neither lost nor at risk on the paretic side (15).

Biglioli et al. (16) reported 20 midface paresis cases treated with dual innervation in two stages. The first stage is CFNG to the preauricular region. The second stage is end-to-end masseterofacial anastomosis accompanied by end-to-side coaptation of CFNG distal to the coaptation site of masseterofacial anastomosis.

Besides the debates on the surgical management of facial paralysis cases, follow-up and objective recovery measurements are not well described. Outcome measures in facial palsy are mainly evaluated by patient-reported outcome measures, clinician-graded scoring systems, and objective software analysis. Patient-reported measures are subjective, but an excellent way to understand the social burden of the effects of facial paralysis. Clinician-graded scoring systems are almost subjective, but none of the scaling systems satisfies all (17).

House-Brackmann (HB) staging is a quick clinical grading system and has been used widely worldwide for many years. However, the HB grading system is mainly dependent on the evaluator and remains insufficient, such as the mouth assessment subpart is far from being adequate in evaluating changes in smile excursion. Thus, the use of a computer-based objective evaluation system has been described in the literature $(8,15,18)$.

Many evaluation systems were introduced in the late 1990s, and there has been a focus on the use of objective metrics in dynamic facial reanimation (19-23). In 2000s, computer analysis software have been used to analyze facial movements (20-22). Developments in artificial intelligence and high-resolution photography/video technology made it possible to evaluate the effects of any facial intervention with more precision.

In 2012 Hadlock and Urban (23) reported using software to detect total facial weakness and zonal facial weakness. They found the software very useful in distinguishing healthy subjects from facial paralysis patients and concluded that the software could be used in rehabilitation follow-ups. Hontanilla et al. (18) reported FACIAL CLIMA evaluation, mainly an optic camera system that recognizes facial movements such as smiling, mouth puckering, and eye closing.

This optical system automatically defines and calculates the vectoral changes with three cameras. However, we have used the Emotrics software that allows user verification for the reference points and calculates the vectors on a static image. That Emotrics software was developed using the standard face databases allow the results to be more realistic, whereas FACIAL CLIMA calculates the dynamic vectoral changes in the same patient. The disadvantage of Emotrics is the need for high-quality photographs (18). 
Since objective was to address and repair the symmetry, the SMILE system which evaluates the smile relative to the healthy side was used. One of the limitations of this study is the limited sample size, but on the other hand, it brings novelty in terms of reporting quantitative outcomes of an intervention using novel outcome measures. Using quantitative outcome measures and artificial intelligence software is crucial for the comparison of different interventions. These tools have the potential to offer a universal and automated outcome measures in the future.

\section{Conclusion}

Facial paralysis patients with asymmetric smile benefit from distal masseter-to-facial nerve transfer, which improves smile excursion dramatically. Further studies are required to confirm these findings.

Ethics Committee Approval: Ethics committee approval was received for this study from the Başkent University Institutional Review Board (Approval Date: June 16, 2020; Approval Number: KA20/241).

Informed Consent: Informed consent was obtained from the patients who participated in this study.

Peer-review: Externally peer-reviewed.

Author Contributions: Concept - B.Ö., O.H.Ç.; Design - B.Ö., O.H.Ç.; Supervision - B.Ö., O.H.Ç.; Resources - B.Ö., O.H.Ç.; Materials - B.Ö., O.H.Ç.; Data Collection and/or Processing - B.Ö., O.H.Ç.; Analysis and/or Interpretation - B.Ö., O.H.Ç.; Literature Search - B.Ö., O.H.Ç.; Writing - B.Ö., O.H.Ç.; Critical Reviews B.Ö., O.H.Ç.

Conflict of Interest: The authors have no conflicts of interest to declare.

Financial Disclosure: This study was supported by Başkent University Research Fund.

\section{References}

1. Nellis JC, Ishii M, Byrne PJ, Boahene KDO, Dey JK, Ishii LE. Association among facial paralysis, depression, and quality of life in facial plastic surgery patients. JAMA Facial Plast Surg 2017; 19: 190-6.

2. Albathi M, Oyer S, Ishii LE, Byrne P, Ishii M, Boahene KO. Early nerve grafting for facial paralysis after cerebellopontine angle tumor resection with preserved facial nerve continuity. JAMA Facial Plast Surg 2016; 18: 54-60.

3. Spira M. Anastomosis of masseteric nerve to lower division of facial nerve for correction of lower facial paralysis. Preliminary report. Plast Reconstr Surg 1978; 61: 330-4.

4. Klebuc MJ. Facial reanimation using the masseter-to-facial nerve transfer. Plast Reconstr Surg 2011; 127: 1909-15.

5. Murphey AW, Clinkscales WB, Oyer SL. Masseteric nerve transfer for facial nerve paralysis. JAMA Facial Plast Surg 2018; 20 : 104-10.
6. Collar RM, Byrne PJ, Boahene KDO. The subzygomatic triangle: rapid, minimally invasive identification of the masseteric nerve for facial reanimation. Plast Reconstr Surg 2013; 132: 183-8.

7. Borschel GH, Kawamura DH, Kasukurthi R, Hunter DA, Zuker RM, Woo AS. The motor nerve to the masseter muscle: an anatomic and histomorphometric study to facilitate its use in facial reanimation. J Plast Reconstr Aesthetic Surg 2012; 65: 363-6.

8. Guarin DL, Dusseldorp J, Hadlock TA, Jowett N. A machine learning approach for automated facial measurements in facial palsy. JAMA Facial Plast Surg 2018; 20: 335-7.

9. Bray D, Henstrom DK, Cheney ML, Hadlock TA. Assessing outcomes in facial reanimation: evaluation and validation of the SMILE system for measuring lip excursion during smiling. Arch Facial Plast Surg 2010; 12: 352-4.

10. Le Clerc N, Herman P, Kania R, Tran H, Altabaa K, Huy PT, et al. Comparison of 3 procedures for hypoglossalfacial anastomosis. Otol Neurotol 2013; 34: 1483-8.

11. Altamami NM, Zaouche S, Vertu-Ciolino D. A comparative retrospective study: hypoglossofacial versus masseterofacial nerve anastomosis using Sunnybrook facial grading system. Eur Arch Otorhinolaryngol 2019; 276: 209-16.

12. Pavese C, Cecini M, Lozza A, Biglioli F, Lisi C, Bejor M, et al. Rehabilitation and functional recovery after masseteric-facial nerve anastomosis. Eur J Phys Rehabil Med 2016; 52: 379-88.

13. Lenz Y, Kiefer J, Dietrich F, Stark GB, Eisenhardt SU. Pre-operative masseter muscle EMG activation during smile predicts synchronicity of smile development in facial palsy patients undergoing reanimation with the masseter nerve: a prospective cohort study. J Plast Reconstr Aesthet Surg 2019; 72: 505-12.

14. Hontanilla B, Marre D. Masseteric-facial nerve transposition for reanimation of the smile in incomplete facial paralysis. Br J Oral Maxillofac Surg 2015; 53: 943-8.

15. Frey M, Giovanoli P, Michaelidou M. Functional upgrading of partially recovered facial palsy by cross-face nerve grafting with distal end-to-side neurorrhaphy. Plast Reconstr Surg 2006; 117: 597-608.

16. Biglioli F, Soliman M, El-Shazly M, Saadeldeen W, Abda EA, Allevi $\mathrm{F}$, et al. Use of the masseteric nerve to treat segmental midface paresis. Br J Oral Maxillofac Surg 2018; 56: 719-26.

17. Dusseldorp JR, van Veen MM, Mohan S, Hadlock TA. Outcome tracking in facial palsy. Otolaryngol Clin North Am 2018; 51: 1033-50.

18. Hontanilla B, Marre D, Cabello A. Facial reanimation with gracilis muscle transfer neurotized to cross-facial nerve graft versus masseteric nerve: a comparative study using the FACIAL CLIMA evaluating system. Plast Reconstr Surg 2013; 131: 1241-52.

19. Revenaugh PC, Smith RM, Plitt MA, Ishii L, Boahene K, Byrne PJ. Use of objective metrics in dynamic facial reanimation: a systematic review. JAMA Facial Plast Surg 2018; 20: 501-8.

20. Linstrom CJ, Silverman CA, Colson D. Facial motion analysis with a video and computer system after treatment of acoustic neuroma. Otol Neurotol 2002; 23: 572-9.

21. Sargent EW, Fadhli OA, Cohen RS. Measurement of facial movement with computer software. Arch Otolaryngol Head Neck Surg 1998; 124: 313-8.

22. Linstrom CJ. Objective facial motion analysis in patients with $\mathrm{fa}-$ cial nerve dysfunction. Laryngoscope 2002; 112: 1129-47.

23. Hadlock TA, Urban LS. Toward a universal, automated facial measurement tool in facial reanimation. Arch Facial Plast Surg 2012; 14: $277-82$. 